\title{
Imaging and serum analysis of immune complex formation of radiolabelled infliximab and anti-infliximab in responders and non-responders to therapy for rheumatoid arthritis
}

\author{
C J van der Laken, A E Voskuyl, J C Roos, M Stigter van Walsum, E R de Groot, G Wolbink, \\ B A C Dijkmans, L A Aarden
}

Ann Rheum Dis 2007;66:253-256. doi: 10.1136/ard.2006.057406

Background: Many patients with rheumatoid arthritis are currently successfully treated with infliximab lanti-tumour necrosis factor); however, about $30 \%$ of the patients do not respond to infliximab. One of the postulated hypotheses of not responding is the fast clearance of infliximab due to the development of infliximab-anti-infliximab complexes.

Objective: To investigate the in vivo mechanism of not responding and the role of human anti-chimeric antibodies (HACAs) by using radiolabelled infliximab.

Methods: Two responding and two non-responding patients with rheumatoid arthritis, infused with radiolabelled infliximab, were investigated by both imaging and serum analysis.

Results: Images showed predominant presence of infliximab in blood up to $24 \mathrm{~h}$, with a trend of faster blood clearance and of higher liver/spleen uptake in a non-responding patient. Clinically inflamed joints showed uptake of the drug. The HACA level in the non-responders was high $(1641$ and $1008 \mathrm{U} / \mathrm{ml}$ ), but low or not detectable in responders. Sucrose gradients of serum showed antibody complexes in both nonresponders. Various sizes of antibody complexes, including very large ones, were observed in a non-responder who developed a serious infusion reaction.

Conclusion: Formation of infliximab-anti-infliximab complexes were found in non-responders due to the presence of large amounts of HACA. This finding, supported by both imaging and serum analysis data, may explain failure of infliximab treatment.

C urrently, many patients with rheumatoid arthritis are successfully treated with infliximab, a chimeric antitumour necrosis factor $\alpha$ (TNF $\alpha)$ antibody. ${ }^{12}$ Nevertheless, about $30 \%$ of the patients do not respond. One of the postulated hypotheses of no response is the fast clearance of infliximab due to the formation of infliximab-anti-infliximab complexes. Support for this hypothesis was found by others in patients with rheumatoid arthritis and in those with Crohn's disease. ${ }^{13}$ A negative correlation was reported between the presence of human antichimeric antibodies (HACAs) with infliximab levels and clinical response. In addition, we have analysed serum of 51 patients with rheumatoid arthritis treated with infliximab. By means of a radioimmunoassay, we observed that $43 \%$ of the patients developed HACAs during a 1-year course of infliximab treatment. ${ }^{4}$ The persistence of HACAs relates to a decrease in therapeutic response, probably due to fast clearance. In monkeys treated with infliximab, formation of antibody complexes was seen after injection of iodine-125-anti-infliximab. ${ }^{5}$ No data on formation of infliximab-anti-infliximab antibody complexes in patients with rheumatoid arthritis are available yet. The process of antibody complex formation in patients with rheumatoid arthritis treated with infliximab and their meaning in non-responders was investigated in this study.

\section{METHODS}

Patients and study protocol

The study was approved by the local ethics committee. Patients fulfilled the criteria of rheumatoid arthritis (according to the American College of Rheumatology Criteria) and were treated with infliximab $(3 \mathrm{mg} / \mathrm{kg})$ with 8 -week intervals at inclusion. Two female responders and two female non-responders to infliximab (age 24-71 years; duration of the disease 638 years) were included. Patients received at least five prior infliximab infusions. The European League Against Rheumatism response criteria were used to determine whether a patient was a responder or a non-responder. ${ }^{6}$ The presence of HACAs was not known at the start of the study. Any comedication was allowed; all included patients were treated with methotrexate.

Eight weeks after the last infusion of infliximab, patients were infused with $10 \mathrm{mg} 740 \mathrm{MBq}$ technetium-99m infliximab in $50 \mathrm{ml} \mathrm{NaCl}(0.9 \%)$ during $2 \mathrm{~h}$. Simultaneously, they received, via the same infusion needle, $3 \mathrm{mg} / \mathrm{kg}(-10 \mathrm{mg})$ unlabelled infliximab in $250 \mathrm{ml} \mathrm{NaCl}(0.9 \%)$ in $2 \mathrm{~h}$. A micropore filter $(0.21 \mu \mathrm{m})$ was used in the infusion application system. Blood samples were withdrawn for further analysis directly before infusion $(t=0 \mathrm{~h})$, during infusion $(\mathrm{t}=5,10$ and 30 min; 1 and $2 \mathrm{~h}$ ) and post infusion $(\mathrm{t}=18$ and $24 \mathrm{~h})$. Images were recorded directly after infusion and $24 \mathrm{~h}$ later.

\section{Imaging}

Infliximab was coupled to ${ }^{99 \mathrm{~m}} \mathrm{Tc}$ as described previously. ${ }^{78}$ ${ }^{99 \mathrm{~m}}$ Tc-infliximab was purified on a PD10 column (PD10 column filled with Sephadex ${ }^{\mathrm{TM}}$ G25M, Amershon, Piscataway, New Jersey, USA) with $0.9 \% \mathrm{NaCl}$ as an eluent and filter sterilised (endotoxin levels $<5$ units $/ \mathrm{ml}$ ). The radiochemical purity, using high-performance liquid chromatography and thin-layer chromatography, was $>99.5 \%$. The immunoreactivity of ${ }^{99 \mathrm{~m}}$ Tc-infliximab, determined using preformed sepharose beads coated with TNF via a non-competing antibody to TNF, ${ }^{9}$ was $>92 \%$.

Whole-body images (matrix $1024 \times 256$ ) and spot views of joints (matrix $256 \times 256$ ) were recorded with an ECAM gamma camera (Siemens, Siemens Mediscle Techniek, Zoetermeer, The Netherlands). Regions of interest were drawn on digital images of the whole-body and on several organs. Whole-body counts were corrected for machine drift, physical decay and counting time differences. Geometrical means were used for analysis. A

Abbreviations: HACA, human anti-chimeric antibody; TNF, tumour necrosis factor 
region of interest in the left ventricle of the heart, corrected for lung background, was used as measure for blood pool activity. Spleen uptake was also corrected for background activity. Ratios of organ uptake to blood pool activity of ${ }^{99 m}$ Tcinfliximab were calculated.

\section{Serum analysis}

Infliximab was quantified as described ${ }^{9}$ with one modification. Infliximab binding was assessed by incubation with biotinylated rabbit immunoglobulin (Ig) G directed to the infliximab idiotype. Detection limit of this assay is about $0.1 \mu \mathrm{g}$ infliximab/ $\mathrm{ml}$ serum. Antibodies to infliximab were measured using a method described previously. ${ }^{10}$ The size of ${ }^{99 \mathrm{~m}}$ Tc-infliximab was analysed by sedimentation analysis on sucrose gradients as described previously. ${ }^{11}$

\section{RESULTS}

\section{Administration of ${ }^{99 m}$ Tc-infliximab to patients}

Infliximab could be safely administered to the two responders (A and B). One non-responder (C) developed a light transient pressure on the chest, but the infusion could safely be continued. A serious infusion reaction was observed in the other non-responder (D), who developed a shock at 45 min of infusion. The infusion was immediately discontinued, followed by proper treatment. The severity of the infusion reaction did not allow this patient to continue the study. Blood samples were collected for up to $30 \mathrm{~min}$; no image data were collected.

\section{Imaging}

Up to $24 \mathrm{~h}$ post infusion, ${ }^{99 \mathrm{~m}}$ Tc-infliximab was mainly present in the blood pool (fig 1). At $24 \mathrm{~h}, 100 \%$ and $98 \%$ of infused ${ }^{99}$ Tc-infliximab were still present in the whole-body of responders $\mathrm{A}$ and $\mathrm{B}$, respectively. A relatively faster plasma and whole-body clearance was found in the non-responder C; the whole-body retention at $24 \mathrm{~h}$ was $76 \%$. Besides blood pool, liver, spleen and kidneys were also visualised. At $2 \mathrm{~h}$, liver uptake in the non-responder was higher than that in the responders, with liver to blood pool ratios of 2.6, 1.5 and 2.2, respectively. Spleen to blood pool ratios showed similar differences. At $24 \mathrm{~h}$, no significant differences in liver and spleen uptake were observed. Uptake of ${ }^{99 \mathrm{~m}}$ Tc-infliximab was seen in clinically inflamed joints (data not shown).

\section{Infliximab and anti-infliximab levels}

Infliximab levels of responder A, negative for anti-infliximab, rose to about $45 \mu \mathrm{g} / \mathrm{ml}$ on infusion (fig $2 \mathrm{~A}$ ). Responder B had low levels of anti-infliximab $(82 \mathrm{AU} / \mathrm{ml})$ at $\mathrm{t}=0$. During infusion, anti-infliximab disappeared and infliximab levels rose to $35 \mu \mathrm{g} / \mathrm{ml}$ (fig $2 \mathrm{~B}$ ). High anti-infliximab levels of 1008 and $1641 \mathrm{U} / \mathrm{ml}$ were found in both non-responders, $C$ and $\mathrm{D}$ respectively (figs $2 \mathrm{C}, \mathrm{D}$ ). The highest level was detected in patient $\mathrm{D}$, who developed the infusion reaction (fig 2D). In both non-responders, all infused infliximab was bound to circulating anti-infliximab within the first $30 \mathrm{~min}$, resulting in low infliximab levels. At 30-60 min of infusion, the concentration of infliximab overruled that of anti-infliximab, resulting in increasing infliximab concentration (fig 2C).

\section{Infliximab-anti-infliximab complexes}

Samples containing sufficient radioactivity ( $\geqslant 30 \mathrm{~min}$ ) were analysed. Sucrose gradients of serum of responder A showed a sharp peak of ${ }^{99 m}$ Tc-infliximab at fraction 18 , exactly the position at which free IgG was found in the nephelometer (fig 3A). This implies absence of infliximab-anti-infliximab complexes. In the responder $\mathrm{B}$, a minor radioactivity shift was seen at 30 and $60 \mathrm{~min}$, probably reflecting the formation of small amounts of small complexes that disappeared later (fig 3B). Higher amounts of small complexes were found in the non-responder $\mathrm{C}$ at 30 and $60 \mathrm{~min}$, with a peak at fraction 15 (fig 3C). Their sedimentation properties corresponded to the formation of $1: 1$ complexes between infliximab and an IgG antibody to infliximab. The serum of non-responder D showed complexes of various sizes (at fraction 15 and lower fractions), including very large ones (molecular weight >1 000 000;

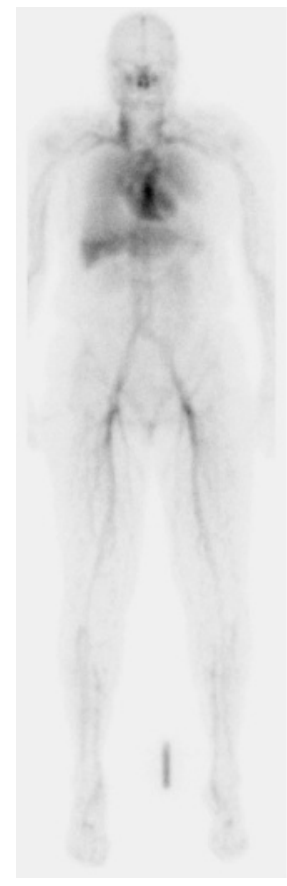

Anterior $2 \mathrm{~h}$

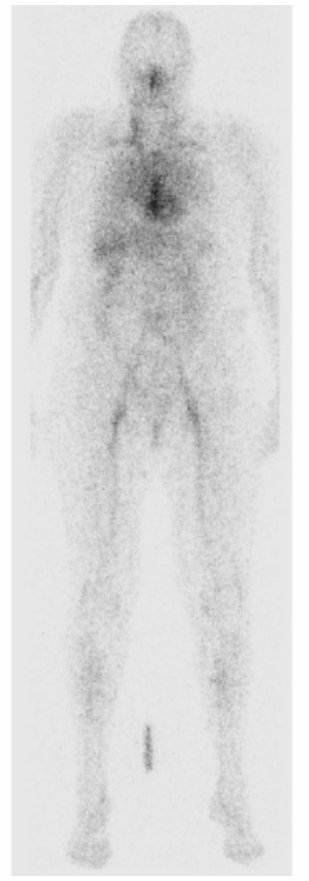

Anterior $24 \mathrm{~h}$

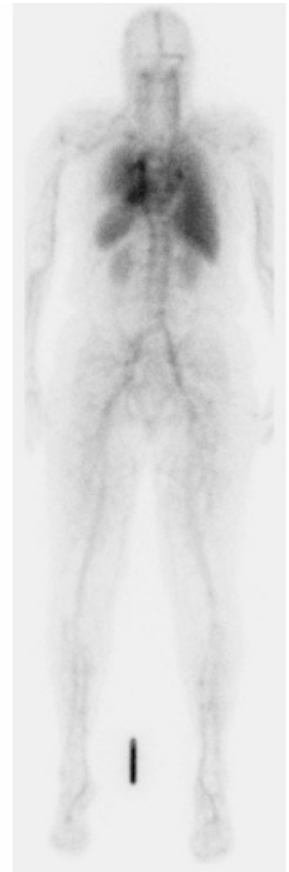

Posterior $2 \mathrm{~h}$

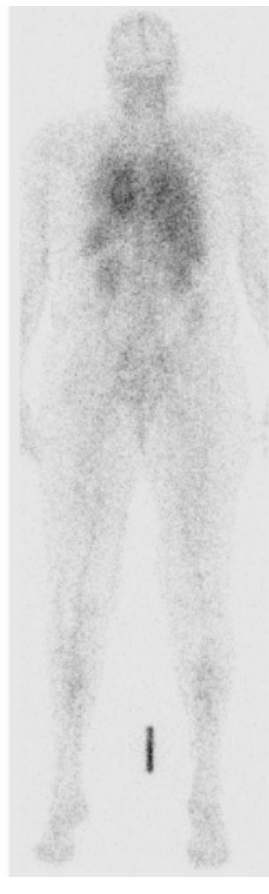

Posterior $24 \mathrm{~h}$

Figure 1 Whole-body images. Anterior and posterior whole-body images of a responder directly after (2 h) and $24 \mathrm{~h}$ post infusion. 

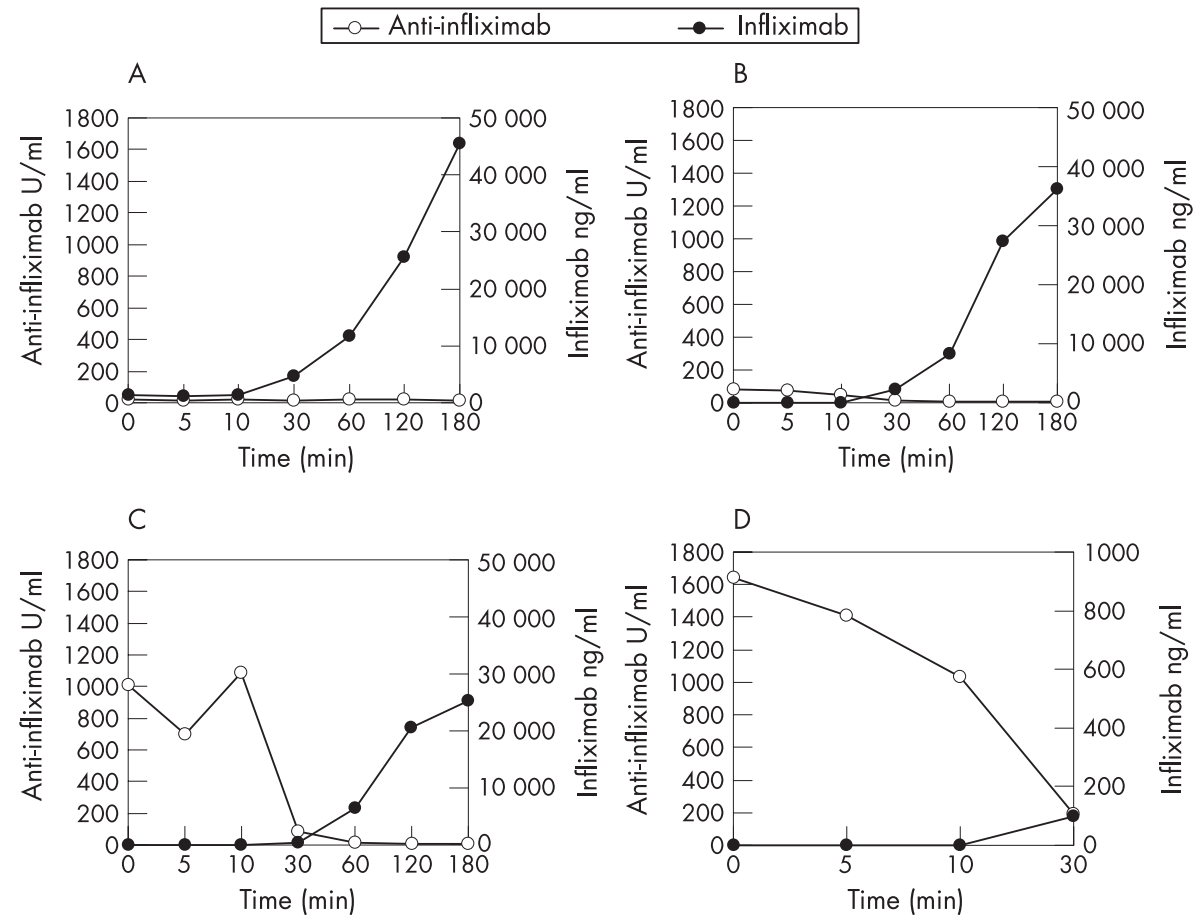

Figure 2 Infliximab and anti-infliximab levels in the sera of responders $A$ and $B(A, B)$ and two non-responders $C$ and $D(C, D)$. (D) The $x$ and $y$ axes were adjusted because of lacking samples after $30 \mathrm{~min}$ of patient $D$ and the lower amount of infliximab in the samples up to $30 \mathrm{~min}$.
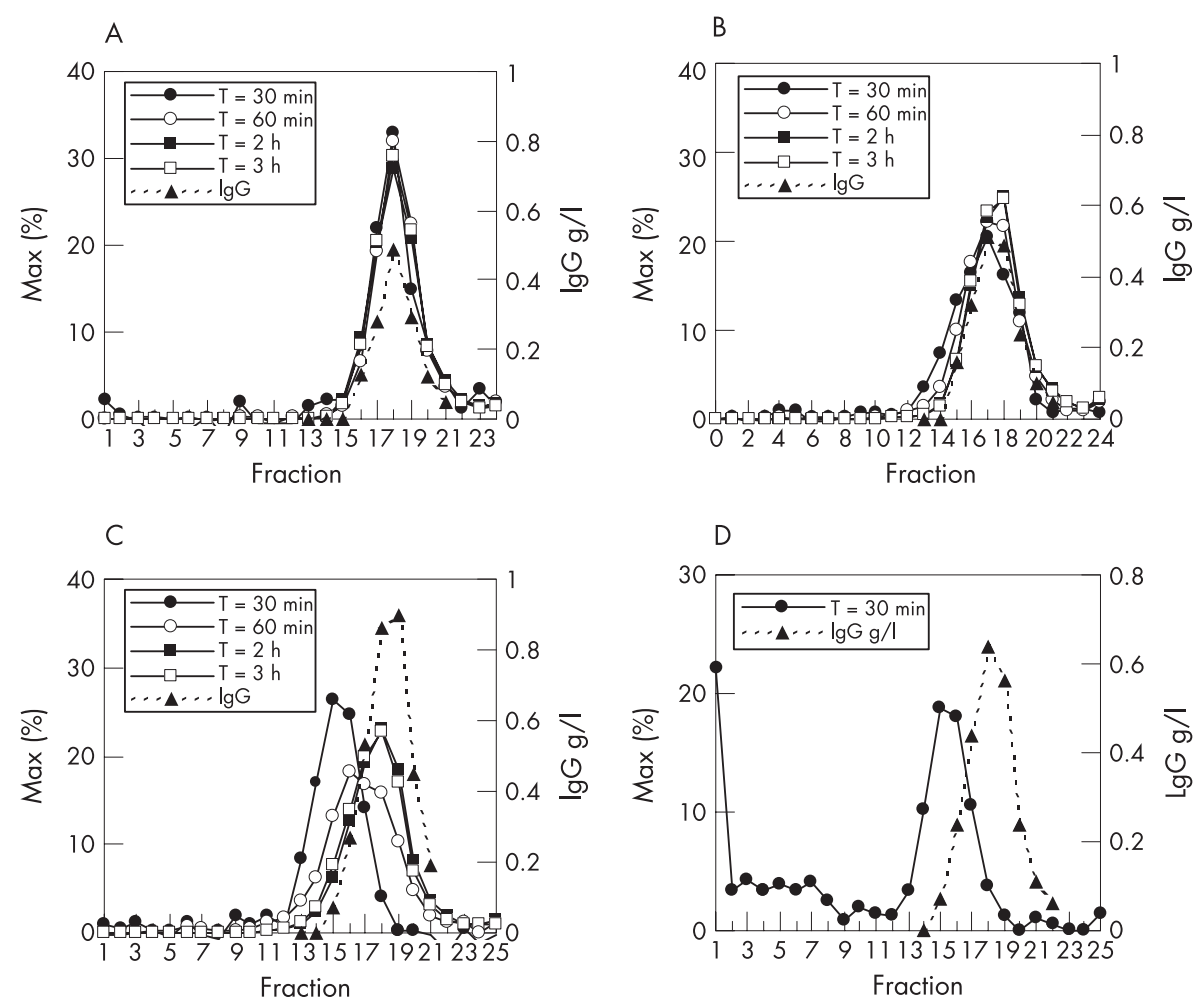

Figure 3 Sucrose gradients of sera of responders $A$ and $B(A, B)$ and of non-responders $C$ and $D(C, D)$. The measured radioactivity in the fractions as a percentage of the maximum radioactivity at each time point (\% of maximum) is shown. The values on the $y$ axis in $D$ have been adjusted to the lower amounts of radioactivity in the 30-min sample to visualise the size of the antibody complexes in this patient. 
fig 3D). From $1 \mathrm{~h}$ onwards, no complexes were found in any of the patients.

\section{DISCUSSION}

To our knowledge, this is the first report of the formation of infliximab-anti-infliximab complexes during infliximab infusion in non-responders with rheumatoid arthritis. Owing to antibody complex formation, low infliximab levels were observed within the first hour of infusion. Images suggested a faster clearance of infliximab in the non-responding patient, possibly by removal of antibody complexes by the liver and spleen. The quantity of HACAs seemed to be important for responsiveness to treatment. Besides a high HACA level, formation of large antibody complexes was involved in the development of a serious infusion reaction in one nonresponder.

The 2-h images showed a trend of faster clearance and higher liver and spleen uptake of ${ }^{99 \mathrm{~m}} \mathrm{Tc}$-infliximab in the nonresponder. Although imaging data of only one non-responder could be collected, these data correspond to the serum analysis findings. Serum analysis showed antibody complex formation within the first hour of infliximab infusion. These antibody complexes are most likely to accumulate in the macrophagephagocyte system, which could explain the relatively faster clearance and higher liver and spleen uptake on the 2-h images. Complex formation was observed in serum up to $60 \mathrm{~min}$; thereafter, the concentration of infliximab overruled that of anti-infliximab and no antibody complexes and no antiinfliximab could be measured anymore. This explains why the images at $2 \mathrm{~h}$, and certainly at $24 \mathrm{~h}$, mainly showed blood pool activity, as biodistribution at these time points was dominated by the concentration of unbound infliximab.

Anti-infliximab levels were high in non-responders. In responder $\mathrm{B}$, small amounts of antibodies were present. The concentration was probably so low that it had not yet affected the responsiveness to treatment. Therefore, we assume that non-response occurs when the concentration of anti-infliximab exceeds a certain critical level. This is confirmed by the results of Beart et al. ${ }^{3}$ In patients with Crohn's disease, they found a shorter duration of response to infliximab with the presence of anti-infliximab levels $>8.0 \mu \mathrm{g} / \mathrm{ml}$. In our study, we calculated that patient $\mathrm{D}$ had about $24 \mu \mathrm{g} / \mathrm{ml}$ of anti-infliximab in the circulation.

Beart $e t \mathrm{al}^{3}$ also described a higher risk of infusion reactions in patients with higher anti-infliximab levels. The finding in our study that development of a serious infusion reaction was observed in the only patient showing formation of large complexes between infliximab and anti-infliximab suggests that besides the quantity of anti-infliximab, the quality of the response is related to infusion reactions.

Our study was an effort to investigate the pathophysiological mechanism of non-response to anti-TNF treatment. Although the number of investigated patients is low, the observations of our study are new and contribute to further knowledge to antiTNF response. Our results showed that the formation of antibody complexes, due to the presence of HACAs, may be responsible for non-response and are most probably responsible for infusion reactions.

\section{ACKNOWLEDGEMENTS}

We thank GAMS van Dongen for his contribution to the design of the study, the radiolabelling of infliximab and his critical revision of the manuscript. We also thank EFI Comans for his help with the infusions of radiolabelled infliximab, EJF Franssen for his contribution to the design of the study and for pharmacological assistance, and $M$ van der Vlies for his calculations of and advice about the radioactivity burden of ${ }^{99 \mathrm{~m}}$ Tc-infliximab.

\section{Authors' affiliations}

C J van der Laken, A E Voskuyl, B A C Dijkmans, Department of Rheumatology, VU University Medical Center, Amsterdam, The Netherlands

J C Roos, Department of Nuclear Medicine, VU University Medical Center, Amsterdam, The Netherlands

M Stigter van Walsum, Department of Otolaryngology/Head and Neck Surgery, VU University Medical Center, Amsterdam, The Netherlands E R de Groot, G Wolbink, L A Aarden, Sanquin Research at CLB and Landsteiner Laboratory and Academical Medical Centre, University of Amsterdam, Amsterdam, The Netherlands

Competing interests: None.

Correspondence to: C J van der Laken, Department of Rheumatology, VU University Medical Center, PO Box 7057, 1007 MB Amsterdam, The Netherlands; j.vanderlaken@vumc.nl

Accepted 5 June 2006

Published Online First 22 June 2006

\section{REFERENCES}

1 Maini RN, Breedveld FC, Kalden JR, Smolen JS, Davis D, MacFarlane JD, et al. Therapeutic efficacy of multiple intravenous infusions of anti-tumor necrosis factor $\alpha$ monoclonal antibody combined with low-dose weekly methotrexate in rheumatoid arthritis. Arthritis Rheum 1998:41:1552-63.

2 Lipsky PE, van der Heijde DMFM, St Clair EW, Furst DE, Breedveld FC, Kalden JR, et al. Infliximab and methotrexate in the treatment of rheumatoid arthritis. AntiTumor Necrosis Factor Trial in Rheumatoid Arthritis with Concomitant Therapy Study Group. N Engl J Med 2000;343:1594-602.

3 Beart F, Noman M, Vermeire S, Van Assche G, D'Haens G, Carbonez A, et al. Influence of immunogenicity on the long-term efficacy of infliximab in Crohn's disease. N Engl J Med 2003;348:601-8

4 Wolbink GJ, Vis M, Lems W, de Groot E, Nurmohamed MT, Stapel S, et al. Development of antiinfliximab antibodies and relationship to clinical response in patients with rheumatoid arthritis. Arthritis Rheum 2006;54:711-15.

5 Rojas JR, Taylor RP, Cunningham MR, Rutkoski TJ, Vennarini J, Jang H, et al. Formation, distribution, and elimination of infliximab and anti-infliximab immune complexes in cynomolgus monkeys. J Pharmacol Exp Ther 2005;313:578-85.

6 Van Gestel AM, Prevoo ML, van't Hof MA, van Rijswijk MH, van de Putte LB, van Riel PL. Development and validation of the European League Against Rheumatism response criteria for rheumatoid arthritis. Comparison with the preliminary American College of Rheumatology and the World Health Organization/Internal League Against Rheumatism criteria. Arthritis Rheum 1996:39:34-40.

7 Visser G, Gerretsen M, Herscheid J, Snow GB, Van Dongen GAMS. Labeling of monoclonal antibodies with ${ }^{186} \mathrm{Re}$ using the MAG3 chelate for radioimmunotherapy of cancer: a technical protocol. J Nucl Med 1993:34:1953-63.

8 Van Gog FB, Visser GWM, Stroomer JWG, Snow GB, Van Dongen GAMS. High dose ${ }^{18}$ Re-labeling of monoclonal antibodies for clinical application: piffalls and solutions. Cancer 1997;80:2360-70.

9 Wolbink GJ, Voskuyl AE, Lems WF, de Groot E, Nurmohamed MT, Tak PP, et al. Relationship between serum trough infliximab levels, pretreatment $C$ reactive protein levels, and clinical response to infliximab treatment in patients with rheumatoid arthritis. Ann Rheum Dis 2005;64:704-7.

10 Aalberse RC, van Loghem E, van Munster PJ, Nadorp JH. Human antibodies to IgE: a simple method to avoid ambiguous results of the radioimmunosorbent test (RIST). J Lab Clin Med 1974:83:831-9.

11 Aarden LA, de Groot ER, Feltkamp TE. Immunology of DNA. III. Crithidia luciliae, a simple substrate for the determination of anti-dsDNA with the immunofluorescence technique. Ann N Y Acad Sci 1975;254:505-15. 